\title{
Efforts in Improving Investment Environment: The Perspective from PCI of Thai Nguyen Province, Vietnam
}

\author{
Nguyen Thi Thu Ha, Ta Thi Thanh Huyen, and Do Thi Hoa Nha
}

\section{ABSTRACT}

\begin{abstract}
The improvement of investment environment and the enhancement of provincial competitiveness is the important development strategies of all provinces and cities in Vietnam. The PCI index is an objective and honest reflection of the investment environment of each locality, so raising this index is also an effort in improving the investment environment. This article focuses on analyzing and evaluating the competitiveness and investment environment of Thai Nguyen province through the PCI index and its components. Some solutions have been proposed to improve PCI as well as the investment environment of the province in the coming time.
\end{abstract}

Keywords: Investment environment, PCI, Provincial ccompetitiveness, Thai Nguyen, Vietnam.

\author{
Submitted : June 30, 2021 \\ Published : July 23, 2021 \\ ISSN: $2507-1076$ \\ DOI: $10.24018 / \mathrm{ejbmr} .2021 .6 .4 .963$ \\ Nguyen Thi Thu Ha * \\ Faculty of Economics, Thai Nguyen \\ University of Economics and Business \\ Administration (TUEBA), Vietnam. \\ (e-mail: ntthuha@tueba.edu.vn) \\ Ta Thi Thanh Huyen \\ Training Department, Thai Nguyen \\ University of Economics and Business \\ Administration (TUEBA), Vietnam. \\ Do Thi Hoa Nha \\ Faculty of Economics, Thai Nguyen \\ University of Economics and Business \\ Administration (TUEBA), Vietnam. \\ *Corresponding Author
}

\section{INTRODUCTION}

The investment and business environment of each locality is a combination of local factors that affect investment activities and economic development. A good business and investment environment not only create favorable conditions for investment activities but also for production and business activities of enterprises. It can be said that the investment environment is the key to attracting investment in the locality.

Currently, to evaluate the investment and business environment in provinces and cities in Vietnam, the Provincial Competitiveness Index (PCI) has been used. This is an index that evaluates and ranks the governments of 63 provinces and cities in Vietnam on the quality of economic management and building a favorable business environment for the development of private enterprises. PCI is built on the basis of assessment of enterprises, so this index objectively and honestly reflects the local business and investment environment. Therefore, PCI is considered an important "voice" of private enterprises about the local business environment, a reliable reference channel on investment locations, and an important driving force for improvement of provincial investment environment.

In the context of international economic integration and industrial revolution 4.0, Thai Nguyen province is strongly transforming, gradually rising up, striving to become a modern industrial economic center of the Northern Midlands and Mountains region and Hanoi Capital region by 2030 according to the Resolution of the $20^{\text {th }}$ Thai Nguyen Provincial Party Congress. The political system of Thai Nguyen province over the years has made efforts to effectively implement the Government's policies, and at the same time research, promulgate and implement policies on improving the investment environment, achieved many successes in improving provincial competitiveness, in particular, improving the PCI index, as well as the component indexes of the PCI. In recent years, the investment environment of Thai Nguyen province has improved a lot, reflected in the increase in the number of investment projects, especially FDI projects in the province, and the improvement of the PCI and its' sub-indexes. In the last 2 years, Thai Nguyen province ranked $1^{\text {st }}$ in terms of scores as well as rankings in the northern mountainous region of Vietnam. Although, the province's PCI scores in 2016 and 2019 are ranked in the "High" group, but just in the "Mid-high" group in 2017, 2018 and 2020. PCI rank of Thai Nguyen province compared to 63 provinces and cities nationwide in 2020 was $11 / 63$. Although the PCI sub - indexes have improved, there are still many limitations, the scores are not high, making the PCI score of the province still poor compared to many other provinces and cities. This study focuses on analyzing the PCI as well as the PCI sub-indexes of Thai Nguyen province in the period 2016-2020, and compares it with some other typical provinces. Activities and achievements in environmental improvement in Thai Nguyen province are also analyzed and evaluated in this study. On that basis, this study proposes a number of solutions to improve the PCI index of Thai Nguyen province, creating a great effort for improving the province's investment environment in the coming time. 


\section{Methodology}

This research used the data sets on PCI and its' sub- indexes (Entry Cost, Access to Land, Transparency, Time Costs, Informal Charges, Policy Bias, Proactivity, Business Support Services, Labor Policy, Law \& Order) from the annual PCI report of the Vietnam Chamber of Commerce and Industry (VCCI) and the United States Agency for International Development (USAID).

In addition, the research collected and used other secondary data from reports of Thai Nguyen Department of Planning and Investment; data from Thai Nguyen General Statistics Office, scientific journals, etc.

A number of methods of data processing and analysis are used such as: Descriptive statistics using data tables or charts; comparative analysis method (comparison of data over time series, comparison between provinces, between indicators).

\section{RESULTS AND DISCUSSION}

\section{A. PCI Index of Thai Nguyen Province, 2016-2020}

In the years from 2016 to 2020, Thai Nguyen province is always in the group of High and Mid-high. Compared to other provinces across the country, Thai Nguyen's scores and rankings in recent years have always been in a high position and have not had many major changes.

In 2016, Thai Nguyen was ranked in the group of provinces with PCI index in the "High" management group with a score of 61.82 , ranked 7 th out of 63 provinces and cities nationwide and ranked 4th out of 14 mountainous provinces in the North. By 2017 and 2018, Thai Nguyen province's ranking dropped to $15 / 63$ and $18 / 63$ across the country, classified as "Midhigh". However, Thai Nguyen still ranks second in the PCI ranking of northern mountainous provinces, after Lao Cai province. At the conference to evaluate performance in 2018 , deploy tasks in 2019 and implement Resolution No. 09NQ/TU of the Provincial Party Committee on improving the business environment, enhancing provincial competitiveness, the delegates raised outstanding issues such as: The awareness of PCI of some localities, units and officials is not high, the investigation and survey of enterprises is still limited. Besides, the issues of policies and activities of consulting and supporting businesses; training high-quality labor force as well as the professional capacity of a part of civil servants when performing official duties has not met the requirements. On that basis, Thai Nguyen Provincial People's Committee promulgated policies to implement Resolution No. $09 \mathrm{NQ} / \mathrm{TU}$ of the Provincial Party Committee on improving the business environment and enhancing provincial competitiveness; so in 2019, Thai Nguyen's PCI ranking ranked 12 th out of 63 provinces and cities across the country; leading the group of northern mountainous provinces, also the 5 provinces with the highest score in the period 2016-2020 and in the group of provinces with good governance quality with a total score of 67.71 points, an increase of 6 places and 3.47 points higher than 2018. In 2020, Thai Nguyen's PCI score is 66.56 points, 1.15 points lower than 2019. But the rank is raised one place to $11 / 63$ across the country.
TABLE I: PCI INDEX OF THAI NGUYEN PROVINCE

\begin{tabular}{cccccc}
\multicolumn{6}{c}{ TABLE I: PCI INDEX OF THAI NGUYEN PROVINCE } \\
\hline Indicators & 2016 & 2017 & 2018 & 2019 & 2020 \\
\hline $\begin{array}{c}\text { PCI scores } \\
\text { National } \\
\text { rankings }\end{array}$ & 61.82 & 64.45 & 64.22 & 67.71 & 66.56 \\
$\begin{array}{c}\text { Northern } \\
\text { mountainous }\end{array}$ & 7 & 15 & 18 & 12 & 11 \\
$\begin{array}{c}\text { region rankings } \\
\text { Tier }\end{array}$ & High & $\begin{array}{c}\text { Mid- } \\
\text { High }\end{array}$ & $\begin{array}{c}\text { Mid- } \\
\text { High }\end{array}$ & High & $\begin{array}{c}\text { Mid- } \\
\text { High }\end{array}$ \\
\hline (Source: VCCI and USAID, 2021). & & &
\end{tabular}

It can be seen that from the perspective of private enterprises, the quality of economic management of the province has improved, but it is not stable and varies from time to time. Therefore, it is necessary to consider and analyze the components of the PCI index and find out the reasons for the decrease in Thai Nguyen's PCI score. If the PCI score is low, it means that the quality of economic management decreases, making it less attractive to investors.

A comparative study of Thai Nguyen province's PCI across regions shows that Thai Nguyen has taken the lead in PCI among provinces in the northern mountainous region of Vietnam in 2019 and 2020. But still lower when comparing to many other provinces in the northern region of Vietnam. The study compares the competitiveness of Thai Nguyen province in 2020 with some provinces in the North of Vietnam such as Quang Ninh, Bac Giang, Bac Ninh, Vinh Phuc through comparative analysis of the PCI index. Standing at the top position in the country for 4 years (20172020) is Quang Ninh province, which is the province for 8 consecutive years in the top 5 provinces and cities with the best quality of economic management in the country. Thai Nguyen province in 2020 has PCI ranked 11th in the country, right behind Bac Ninh province (ranked 10, with PCI score 0.18 points more than Thai Nguyen's PCI). In the group of provinces compared, Thai Nguyen province has PCI with significantly higher scores and rankings than Bac Giang and Vinh Phuc.

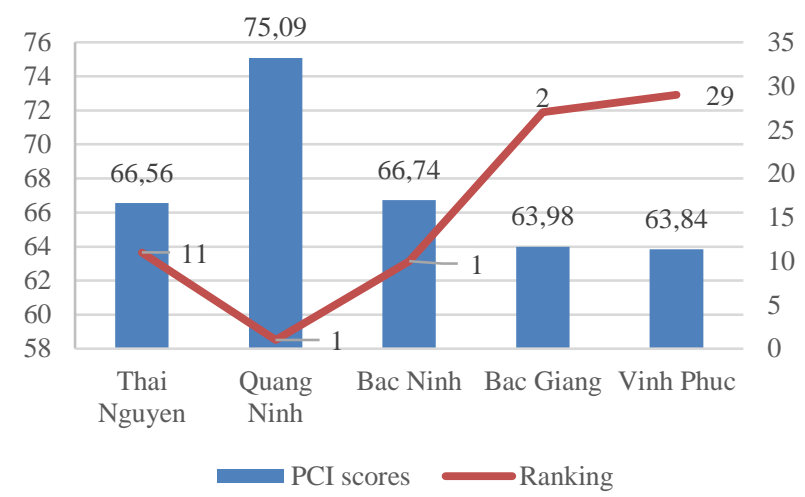

Fig. 1. PCI comparison of Thai Nguyen province with some other provinces in the North. (Source: VCCI and USAID, 2021).

\section{B. Analysis of PCI Sub-index of Thai Nguyen Province}

During the period 2016-2020, the PCI sub-indices of Thai Nguyen province have had significant changes. Sub-indices have high scores such as Entry Cost, Labor Policy and Law $\&$ Order. Besides, there are sub-indices that are still low compared to other localities across the country such as Business Support Services, Policy Bias. 
TABLE II: PCI SUB-INDICES OF THAI NGUYEN

\begin{tabular}{cccccc}
\hline \multirow{2}{*}{ PCI sub-indexes } & \multicolumn{5}{c}{ Scores } \\
\cline { 2 - 6 } & 2016 & 2017 & 2018 & 2019 & 2020 \\
\hline Entry Cost & 8.62 & 7.27 & 6.91 & 7.36 & 8.35 \\
Access to Land & 5.76 & 6.45 & 6.37 & 6.07 & 6.68 \\
Transparency & 6.16 & 6.31 & 6.12 & 6.69 & 5.85 \\
Time Costs & 6.64 & 6.17 & 6.40 & 6.63 & 7.70 \\
Informal & 5.76 & 5.66 & 5.93 & 6.31 & 6.89 \\
Charges & 5.20 & 5.16 & 5.80 & 6.59 & 6.29 \\
Policy Bias & 5.32 & 6.05 & 6.26 & 6.55 & 7.39 \\
Proactivity & & & & & \\
Business & & & & \\
Support & 4.89 & 6.00 & 5.81 & 6.05 & 5.63 \\
Services & & & & & \\
Labor Policy & 7.64 & 7.70 & 7.69 & 7.88 & 7.42 \\
Law \& Order & 5.84 & 6.42 & 6.40 & 7.13 & 7.34 \\
\hline Saberyyyyy
\end{tabular}

(Source: VCCI and USAID, 2021).

\section{Entry Cost Index}

In previous PCI surveys, the Entry Cost was always best performed by the provinces in the ten areas of the provincial business environment. This trend is also clearly shown in the PCI results of Thai Nguyen. In Thai Nguyen's PCI surveys, it is shown that Entry Cost is the indicator with the highest score among the indicators. This result has shown the considerable efforts of the provincial government to simplify the procedures for registration and establishment of enterprises.

The score of the Entry Cost index increased and decreased continuously, from 8.62 points in 2016 to 6.91 points in 2018 (decline 1.71 points). By 2019 it will increase to 7.36 points and continue to increase until 2020 (reaching 8.35 points, an increase of 1.44 points compared to 2018). This index of Thai Nguyen province in 2020 ranks 13th out of 63 across the country. Compared with other PCI sub - indices, the Entry Cost index of Thai Nguyen province has the largest increase in the period 2016-2020.

This result shows that the People's Committee of Thai Nguyen province has made great efforts in researching, reviewing, and at the same time developing documents to amend, supplement, replace or abolish regulations on administrative procedures that are no longer appropriate; strengthened to promote the reform of administrative procedures, implement the "one-door", "one-stop shop" in the state administrative agencies.

In addition to the results achieved in improving and maintaining the PCI index, Thai Nguyen still has problems that need to be improved such as coordination and information sharing among state agencies in handling procedures. Administration for businesses, investors is not flexible, regulations on coordination between departments, departments and sectors are not really well implemented. In the dialogue and support for businesses, some branches and localities are still absent, have not well complied with the assignment and direction of the Provincial People's Committee in answering questions for businesses in the area when required. In addition, the coordination in reporting and evaluating the performance of some units is still slow and not timely; compensation, site clearance, resettlement arrangement and implementation of land procedures are still facing difficulties and obstacles; the application of information technology in management, exploitation and publicity and transparency of administrative procedures has not been thoroughly implemented.

\section{Access to Land}

Access to land is considered an important indicator in the competitiveness and investment attraction of localities, reflecting the ease of access to land and the assurance of stability in the land use process that businesses are interested in. In the period 2016-2020, the land access index of Thai Nguyen province compared to other indicators has not improved significantly.

In 2016, the land access index reached 5.76 points; By 2017 this index increased to 6.45 points (an increase of 0.69 points compared to 2016). In 2019, the score of this indicator was 6.07 points, a decrease of 0.38 points compared to 2017 which was also two consecutive years of reduction; By 2020, the score was improved to 6.68 points and ranked 31 st out of 63 provinces and cities across the country.

\section{E. Transparency}

In the period 2016-2020, the transparency index of Thai Nguyen province compared to other component indexes did not improve significantly. In 2016, this index reached 6.16 points; in 2017 increased to 6.31 points; by 2018 again decreased to 6.12 points. In 2019, the transparency index reached 6.69 points, up 0.57 points and 11 places higher than in 2018 , reaching the 29 th out of 63 provinces and cities across the country. In 2020 , the score dropped to 5.85 points and ranked $32 / 63$ in the country.

Most businesses believe that budget documents are published after approval by agencies and individuals and are detailed enough for businesses to use in their production and business activities. However, for planning documents, it is difficult for businesses to access. Not only lack of transparency and publicity of information, but the implementation of regulations in the province is also very limited and businesses are difficult to predict.

\section{F. Time Costs}

Compared to other provinces in the region, Thai Nguyen is always ranked in the top 3 provinces in terms of time and cost to implement State regulations. In 2016, the time cost score reached 6.64 points and dropped to 6.17 points in 2017. A year later, the score increased to 6.40 points and the score continued to increase for 3 years. consecutively reaching 6.63 points in 2019 and reaching 7.70 points in 2020, this is the highest score in the whole period. Thai Nguyen's Time Costs index ranks $34^{\text {th }}$ out of 63 provinces and cities nationwide in 2020 .

Besides the achieved results, some things need to be changed such as reducing the time to carry out administrative procedures, positively changing the attitude and behavior of officials and staffs when dealing with businesses.

\section{G. Informal Charges}

Informal cost is an indicator with unstable scores for the period 2016-2020. This index decreased from 5.76 in 2016 to 5.66 in 2017 . From 2018 to 2020 , the index's score tends to increase, increasing from 5.93 in 2018 to 6.89 in 2020 , ranking 20/63 in the country.

According to VCCI (2019), still up to 54\% of enterprises in Thai Nguyen province reflect that they have to pay informal fees; by 2020 it will decrease to $47 \%$, down $7 \%$ compared to 2019. Informal expenses are quite common and exist to the extent that enterprises consider them normal and 
within acceptable limits. The province has a view to create the best conditions for businesses to operate and develop as tax administrative procedures have been significantly improved, although there are still many complaints about tax registration procedures, changes in information Tax information and tax refund, tax inspection, etc. However, in reality, the problems that cause difficulties for enterprises are concentrated mainly on the officials who directly work with enterprises from business registration, business establishment, tax activities, market management... The main reason for businesses to accept informal expenses is the mentality of wanting to work quickly and the working attitude of some officials and civil servants who deliberately causing harassment, make it difficult for businesses.

\section{H. Policy Bias}

The Policy Bias index of Thai Nguyen province is determined from 2016 to 2020 and tends to be improved. From 2016 to 2018 , this index has a relatively low rating, with 5.20 points in 2016; in 2017 decreased to 5.16 points; 2018 rose to be a little insignificant with a score of 5.80. By 2019, the Policy Bias index increased to the highest level in the whole period, with 6.59 points and an increase of 0.79 points compared to 2018 . In 2020 it decreased to 6.29 points, less 0.3 points compared to 2019 ; but this is still an improved score compared to 2016. This index of the province ranks lowest in 2020 in the PCI sub-index, ranking 45/63 provinces across the country.

Through the process of surveying VCCI over the years, the survey results show that "unfair competition is present in all localities across the country to varying degrees". This also shows that although the criteria of equal competition tend to increase, in fact, many businesses are still concerned about the province's preferential treatment for state-owned enterprises, FDI enterprises, and large economic groups. affecting and causing difficulties to the production and business activities of enterprises in the province, especially small and micro enterprises. The reason is that the main source of business falls into the familiar enterprises of officials and agencies, which shows the alarming situation and the equality in competition among enterprises in the province was a lot of limitation.

\section{Proactivity}

The Proactivity index is one of the indicators with the most obvious improvement in the PCI sub-index of Thai Nguyen province. In 2016 the proactivity index reached 5.32 points, and in 2017 increased to 6.05 points, up 1.07 points compared to 2016 . This index continued to increase to 6.26 points in 2018 ; increased to 6.55 points in 2019 ; and increase to 7.39 points in 2020, which is the highest score in the whole period. It can be seen that this index has markedly improved, increasing for 4 consecutive years; from 5.32 points in 2016 to 7.39 points in 2020 , an increase of 2.07 points. The province's proactivity has made a remarkable leap, ranking 4th out of 63 nationwide in 2020 .

\section{J. Business Support Services}

In the period 2016-2020, the index of business support services of Thai Nguyen province has unstable changes. In 2016, this index reached 4.89 points, but in 2017 it increased to 6.00 points, then dropped to 5.81 points in 2018. In 2019, the index's score increased to 6,05 points and continued to decrease to 5.63 points in 2020 . The ranking of this index is even lower than the average score of the whole country, ranking 43/63 provinces and cities across the country.

In fact, the administrative procedures related to enterprises are still quite cumbersome; many businesses, especially small businesses, have not yet accessed information about the province's business support services and policies. Besides, the number of units in the province providing technology services, trade promotion or market search, legal advice is not much; The quality of services is not high, the organization of conferences, forums, business dialogues as well as trade promotion and investment promotion events is still limited in both quantity and scale.

\section{K. Labor Policy}

Among the PCI sub-indexes of Thai Nguyen province, the Labor Policy index has a great improvement and has the highest score compared to the PCI sub-indexes of the province. From 2016-2020, the score of the labor policy index is always above 7 . In 2019 , this index reached 7.78 points, the highest in the whole period. By 2020, the score will drop to 7.42 points, 0.36 points lower than in 2019 . This index ranked $7 / 63$ in the whole country in 2020

Besides the efforts of vocational schools, the province's system of job placement centers is also strengthening the connection between workers and businesses to create favorable conditions for workers to find jobs. The centers have actively promoted forms of counseling, job introduction, connection of labor supply-demand, diversification of employment transaction activities; increase frequency, innovate form, improve organizational efficiency through website system, online support, etc.

\section{Law \& Order}

The index of Law \& Order in the PCI sub - indexes of Thai Nguyen province during this period increased continuously in 2016-2020. In 2016, the score of this index reached 5.84 points, the score continuously increased over the years. By 2020, the Law \& Order index reached 7.34 points, an increase of 1.5 points compared to 2016 , this is the highest score in this period and ranks $12 / 63$ in the whole country.

In order to improve this index, provincial leaders have reviewed and perfected institutions and laws; increasing the application of information technology to civil judgment enforcement activities...; strengthen coordination among relevant agencies in civil judgment enforcement; as well as the understanding of the role of civil judgment enforcement in improving the PCI index of civil judgment enforcement officers themselves.

\section{Achievements in Improving Investment Environment of Thai Nguyen Province}

In the period 2015-2020, only foreign investment projects (FDI), Thai Nguyen has attracted 108 projects (up 56 projects compared to the previous period), with a total realized investment capital of 5 billion USD. In which, many largescale projects come from Korea, Hong Kong and Japan such as Alutec Vina Factory of Korea (invested capital of 93.7 million USD); Hong Kong's high-end shirt fabric factory (\$350 million); Up to now, the province has 156 valid FDI projects with a total registered capital of over 8.2 billion USD. 
To achieve the above results, over the years, the Party Committee and authorities in the province have made great efforts to lead and direct the implementation of solutions to improve the investment and business environment. Specifically, the Standing Board of the Provincial Party Committee issued Directive No. 19-CT/TU dated April 18, 2012 on "Continuing to strengthen the leadership of the Party in implementing solutions to improve the provincial competitiveness". From this Directive, the Standing Board of the Provincial Party Committee continued to raise it to Resolution 09 - NQ/TU, dated March 29, 2019 "on improving the business environment, enhancing provincial competitiveness (PCI)". After Resolution 09 was issued, the Provincial People's Committee also promptly issued Plan No. 74-KH/UBND, dated May 24, 2019, to implement Resolution $09-$ NQ/TU of the Standing Board of the Provincial Party Committee.

In recent years, Thai Nguyen province has stepped up the reform of administrative procedures (PAR) to create favorable conditions for people and businesses. This work has achieved many important results, contributing to improving the investment and business environment, promoting socioeconomic development of the province. Currently, Thai Nguyen province has achieved the rate of providing online public services at level 3.4 of Thai Nguyen at 38\%, exceeding the target set out in Resolution No. 17/NQ-CP of the Government (by 2020). reaching 30\%). The administrative reform index of the province is assessed to have made remarkable improvements. In 2019, Thai Nguyen province ranked $14^{\text {th }}$ in the country on the PAR index, up 40 places compared to 2016. Besides the achieved results, the PAR work of the province still has shortcomings and limitations. PAR activities have achieved results but have not yet met the requirements. The direction and administration of PAR in some agencies and units is not really drastic. There is a shortage of human resources to carry out PAR, professional qualifications and training. The application of information technology in the process of solving work between agencies in the province lacks synchronous linkage.

\section{CONCLUSION AND RECOMMENDATION}

The results announced by VCCI and USAID on the Provincial Competitiveness Index (PCI) 2020, Thai Nguyen province ranked $11^{\text {th }}$ out of 63 provinces and cities, with a total score of 66.56 points, up 1 place but down 1.15 points compared to 2019; at the same time is the province with the leading score among 14 northern mountainous provinces. This shows the efforts of the province in running the local economy. However, the decrease in PCI score and the drop to the mid-high group showing that Thai Nguyen province still has a lot of work ahead that needs to be done to enhance its competitiveness and improve the investment environment of the province. The following solutions are proposed to improve the PCI of the province:

1) Promote the reform of administrative procedures:

- Promote reform of administrative procedures, especially those related to business establishment, land, investment, construction, tax declaration and payment, customs, social insurance, etc.

- To attach importance to building and improving the quality of cadres and civil servants.

- Focus on investing in applying information technology in the activities of state management agencies, considering this as a solution to improve working style, affecting efficiency and effectiveness of work.

2) Improve efficiency of land-related activities:

- Pay attention to publicizing the unused land fund in order to make it more transparent to access land resources and production premises, ensure the basis of land allocation and land lease, and help private enterprises to be equal in access to land for production and business;

- Resolutely recover land projects that are not used effectively or for improper purposes.

- Promoting the investment in infrastructure of industrial zones and clusters in the area to solve the problem of premises for production and business in order to support enterprises to have production and business premises.

Strengthen the publicity and transparency of information for the business community

- Disclosure and transparency of information for the business community and people, especially planning and information on investment projects.

- Improve the operation quality of the web portal of the province and departments.

- Disseminate and publicize legal documents promulgated by central agencies; planning, plans, administrative procedures and documents directing the administration of the province on the provincial web portal, departments, divisions, branches and at part one of receiving dossiers and procedures for investors can easily access, do not spend much time searching.

3) Enhance the proactivity and pioneering of leaders at all levels:

- Organize activities to meet, contact and remove difficulties and obstacles for investors and businesses at different levels and sectors (provincial level, local level, specialized department level), support investors investment, enterprises thoroughly solve difficulties and problems.

- Develop programs to support businesses, especially small and medium enterprises, start-up businesses in terms of legal, market information, business strategy, labor training, trade promotion, brand promotion, access to information and expand the market, etc.

4) Improve the efficiency and quality of legal institutions:

- Continue to improve the efficiency and quality of operations of local legal institutions in order to create trust of enterprises.

- Implement well the legal support program for businesses in the province.

- Improve the quality in the adjudication of business cases, creating trust for enterprises.

- Consolidate the role of the Bar Association, notary offices, law firms, legal organizations in providing legal support and advice, and protecting the legitimate interests of enterprises.

- Strengthen the review and promptly propose to competent agencies to amend, supplement and replace invalid legal documents. 


\section{REFERENCES}

[1] Le Thi Thanh Thuy, Pham Thi Thu Huong, Le Van Cuong, "Improving the provincial competitiveness index of Phu Tho province", Journal of Science and Technology, University of Hung Vuong, vol. 17, no. 4, pp. 51-65, 2019.

[2] Ngo Phuc Hanh, Dao Van Hung, Nguyen Thac Hoat, and Dao Thi Thu Trang, "Improving quality of foreign direct investment attraction in Vietnam", International Journal of Quality Innovation, vol. 3, No. 7, pp: 1-16, 2017.

[3] Provincial Competitiveness Index. https://pcivietnam.vn.

[4] Thai Nguyen Provincial Party Committee, Resolution of the Standing Board of the Provincial Party Committee on improving the business environment and enhancing provincial competitiveness (PCI), March 2019.
[5] Thai Nguyen Provincial People's Committee, Implemented Resolution No. 09/NQ/TU dated March 29, 2019 of the Standing Board of the Provincial Party Committee on improving the business environment and enhancing provincial competitiveness, May 2019.

[6] Thai Nguyen Provincial People's Committee, Report on implementation of socio-economic tasks in 2020; socio-economic objectives and tasks in 2021. No. 208/BC-UBND, November 2020.

[7] Thanh Tung, Diep, "Additional Approaches to Assess the Vietnam Provincial Competitiveness Index (PCI)", International Business Research, vol. 7, No. 3, pp. 1-12, February 2014.

[8] VCCI \& USAID. Vietnam Provincial Competitiveness Index 20162020. https://pcivietnam.vn/uploads//VN-Bao-cao-dai-PCI/Bao-caoPCI-2020.pdf. 